\title{
Modal Method Analysis of Quantum-Dot Nanowires for Single Photon Sources
}

\author{
Gür, Ugur Meriç; Gregersen, Niels; Arslanagic, Samel; Mattes, Michael
}

Published in:

Proceedings of the 20019 International Conference on Electromagnetics in Advanced Applications (ICEAA)

Link to article, DOI:

10.1109/ICEAA.2019.8879036

Publication date:

2019

Document Version

Publisher's PDF, also known as Version of record

Link back to DTU Orbit

Citation (APA):

Gür, U. M., Gregersen, N., Arslanagic, S., \& Mattes, M. (2019). Modal Method Analysis of Quantum-Dot Nanowires for Single Photon Sources. In Proceedings of the 20019 International Conference on Electromagnetics in Advanced Applications (ICEAA) IEEE. https://doi.org/10.1109/ICEAA.2019.8879036

\section{General rights}

Copyright and moral rights for the publications made accessible in the public portal are retained by the authors and/or other copyright owners and it is a condition of accessing publications that users recognise and abide by the legal requirements associated with these rights.

- Users may download and print one copy of any publication from the public portal for the purpose of private study or research.

- You may not further distribute the material or use it for any profit-making activity or commercial gain

- You may freely distribute the URL identifying the publication in the public portal 


\title{
Modal Method Analysis of Quantum-Dot Nanowires for Single Photon Sources
}

\author{
Uğur Meriç Gür*(1), Niels Gregersen ${ }^{(2)}$, Samel Arslanagić( ${ }^{(1)}$ and Michael Mattes ${ }^{(1)}$ \\ Technical University of Denmark, (1) Dept. of Electrical Engineering, (2) Dept. of Photonics Engineering, \\ Kgs. Lyngby, Denmark, e-mail: umgur@elektro.dtu.dk
}

Within optical quantum information processing, the quantum bits are encoded on single photons, and a key component is thus a source capable of producing single indistinguishable photons on demand. However, designing a single-photon source combining simultaneously photon purity and indistinguishability with high extraction efficiency remains a challenge [1]. Nanowires with embedding semiconductor quantum dots have recently emerged as an attractive platform [1] for deterministic single-photon generation. For design purposes, the efficient simulation of a quantum-dot nanowire system is required. One of the most efficient and convenient approaches is the modal method as it can exploit symmetry properties of the structure and provides insight into the physical behavior of a system such as propagation constants of the modes and modal scattering coefficients [2]. In this contribution, the coupling problem of a quantum dot and a dielectric nanowire is modelled and efficiently simulated using a full vectorial modal method employing open boundaries to avoid spurious reflections [3]. Therefore, matched or absorbing layers are not required. In addition to conventional circular structures, elliptical structures, which can supply a true monomode and allow controlling the polarization [4], are analyzed.

The method is based on dividing the geometry into uniform layers along the propagation axis and expanding the in-plane eigenmodes into TM and TE modes. In this way, calculation of the coupling integrals is significantly simplified. For the expansions, appropriate functions are used to take advantage of the symmetry conditions forced by the structure, such as Bessel functions for a circular or Mathieu functions for an elliptical nanowire. The eigenvalue problem obtained from Maxwell's equations yields the corresponding expansion coefficients. With the described method, the coupling efficiency can be easily calculated using $[5] \beta=\Gamma_{\mathrm{F}} /\left(\Gamma_{\mathrm{F}}+\Gamma_{\mathrm{G}}+\Gamma_{\mathrm{Rad}}\right)$, where $\beta$ is the coupling efficiency to the fundamental mode, $\Gamma_{\mathrm{F}}, \Gamma_{\mathrm{G}}$ and $\Gamma_{\mathrm{Rad}}$ represent spontaneous emission rate into fundamental mode, other guided modes and radiation modes, respectively. As an example, circular nanowires having different radii are excited with a quantum dot at the center. The structure is analyzed with the described method, and computed normalized spontaneous emission rates and the coupling efficiencies are given in Figure 1. Results are consistent with the literature [3]. As the simulation is order of magnitudes faster than for example a finite element method, the presented method can be used for design purposes, thus paving the way of engineering the vicinity of the quantum dot to obtain very high coupling efficiencies for single photon sources.

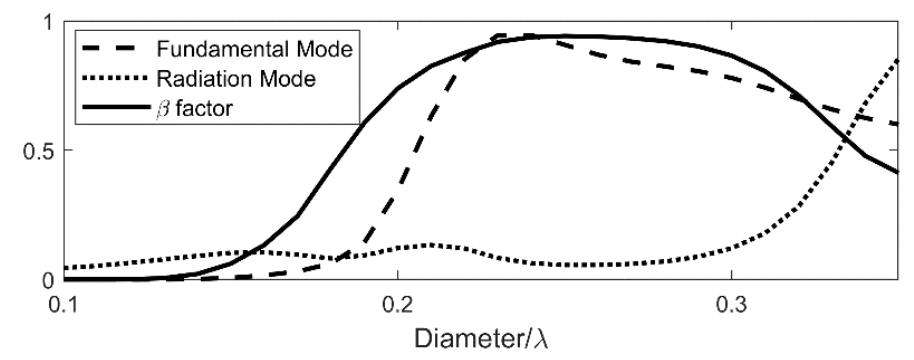

Figure 1. Normalized spontaneous emission rates for the fundamental mode and radiation modes with the correspondant coupling efficiency for circular nanowires excited by a quantum dot.

This work has been funded by Villum Fonden (VKR Center of Excellence NATEC-II, grant 8692).

1. P. Senellart, G. Solomon, and A. White, "High-performance semiconductor quantum-dot single-photon sources", Nat. Nanotechnol., vol. 12, no. 11, 2017, pp. 1026-1039.

2. A.V. Lavrinenko, J. Lægsgaard, N. Gregersen, F. Schmidt, T. Søndergaard, Numerical methods in photonics, CRC Press., 2014.

3. T. Häyrynen, J.R. de Lasson, N. Gregersen, "Open-geometry Fourier modal method: modeling nanophotonic structures in infinite domains", J. Opt. Soc. Am. A, vol. 33, no. 7, 2016, pp.1298-1306.

4. M. Munsch, J. Claudon, J. Bleuse, N.S. Malik, E. Dupuy, J.M. Gérard, Y, Chen, N. Gregersen, J. Mørk, "Linearly polarized, single-mode spontaneous emission in a photonic nanowire", Phys. Rev. Lett., vol. 108, no. 7, 2012.

5. N. Gregersen, P. Kaer, J. Mørk, "Modeling and design of high-efficiency single-photon sources", IEEE J. Sel. Top. Quantum Electron., vol. 19, no. 5, 2013. 